\title{
Effects of the lower energy and pulse stacking in carbon dioxide laser skin treatment: an objective analysis using second harmonic generation
}

Marcos Matias Motta ${ }^{1} \mathbb{D}$, Rafael Fantelli Stelini ${ }^{2} \mathbb{B}^{\mathbb{B}}$, Davi Reis Calderoni ${ }^{3} \mathbb{C}$, Rovilson Gilioli ${ }^{4} \mathbb{C}$, Gislaine Vieira Damiani $^{5} \mathbb{B}$, Carlos Lenz César ${ }^{6} \mathbb{D}$, Paulo Kharmandayan ${ }^{7, *}$

1.Fellow PhD Degree. Universidade Estadual de Campinas - Faculty of Medical Sciences - Department of Surgery Campinas (SP), Brazil.

2.MD. Universidade Estadual de Campinas - Faculty of Medical Sciences - Department of Anatomic Pathology - Campinas (SP), Brazil.

3.PhD. Universidade Estadual de Campinas - Faculty of Medical Sciences - Department of Surgery - Campinas (SP), Brazil. 4.PhD, Head. Universidade Estadual de Campinas - Faculty of Medical Sciences - Multidisciplinary Center for Biological Investigation on Laboratory Animals Science - Campinas (SP), Brazil.

5.PhD. Instituto Federal de Educação, Ciência e Tecnologia de São Paulo - Biophotonics Laboratory - Capivari (SP), Brazil.

6.PhD. Universidade Estadual de Campinas - National Institute of Photonics Applied to Cell Biology - Biophotonics Laboratory - Campinas (SP), Brazil.

7.Associate Professor, Head. Universidade Estadual de Campinas - Faculty of Medical Sciences - Department of Surgery

- Campinas (SP), Brazil.

\begin{abstract}
Purpose: To evaluate the effect of fractional carbon dioxide $\left(\mathrm{CO}_{2}\right)$ laser treatment using lower power associated with pulse stacking within collagen fibers, using second harmonic generation microscopy and computerized image analysis. Methods: Twenty male Wistar rats aging eight weeks were used. Each treatment area received a single-pass $\mathrm{CO}_{2}$ fractional laser with different parameters. The 20 animals were divided into two groups and euthanized after 30 and 60 days. Second harmonic generation images were obtained and program ImageJ was utilized to evaluate the collagen organization within all areas. Collagen anisotropy, entropy and optical density were quantified. Results: Increased anisotropy over time was observed in all four areas, but only reached statistical significance $(p=0.0305)$ when the mildest parameters were used (area four). Entropy decreased over time in all areas, but without significance $(p=0.1779)$ in area four. Density showed an overtime increase only in area four, but no statistical significance was reached $(p=0.6534)$. Conclusion: When combined, the results obtained in this study regarding anisotropy, entropy and density tend to demonstrate that it is possible to achieve collagen remodeling with the use of lower power levels associated with stacked pulses.
\end{abstract}

Key words: Lasers. Gas. Skin Aging. Second Harmonic Generation Microscopy. Rats.

*Corresponding author: pkharmand@hotmail.com | (55 11)95020-2080

Received: Dec 14, 2020 | Review: Jan 16, 2021 | Accepted: Mar 11, 2021

Conflict of interest: Nothing to declare.

Research performed at the Multidisciplinary Center for Biological Investigation on Laboratory Animal Science and Division of Plastic Surgery, Department of Surgery, Faculty of Medical Sciences, Universidade Estadual de Campinas (UNICAMP), Brazil. Part of a PhD degree thesis, postgraduate program in Surgical Sciences, Faculty of Medical Sciences, UNICAMP. Tutor: Prof. Dr. Paulo Kharmandayan. 


\section{Introduction}

Skin resurfacing with carbon dioxide $\left(\mathrm{CO}_{2}\right)$ laser is still considered the gold standard treatment for facial rejuvenation. It has been used for this purpose since the early 90 s with impressive results ${ }^{1,2}$. On the other hand, it presents a relatively high rate of drawbacks, as long downtime for recovery and risks for scarring and pigmentary disorders ${ }^{3}$.

Fractioning the laser beam with scanners was initially described by Manstein ${ }^{4}$ with a $1500 \mu \mathrm{m}$ laser prototype. In 2007, Hantash ${ }^{5,6}$ described the $\mathrm{CO}_{2}$ fractional laser. Its principle relied on creating an array of multiple micro areas of tissue vaporization (micro thermal zones - MTZ) while leaving unaffected skin around them. This allowed for faster re-epithelization and recovery time while yielding good clinical results ${ }^{7,8}$.

Although much safer, the fractionated mode can still present some complications, especially when higher fluences are used, as observed by Shamsaldeen ${ }^{9}$.

An alternative for safer fractional $\mathrm{CO}_{2}$ laser treatments could be lowering the energy employed while stacking pulses at the same MTZ. This is already employed in clinical practice and usually delivers reliable results. An experimental study showed that using lower power associated with pulse stacking (consecutive pulses at the same location) can sustain higher macroscopic tissue contraction after 60 days compared to the use of high energy with a single pulse ${ }^{10}$.

In this study, we objectively evaluate this effect within collagen fibers using second harmonic generation (SHG) microscopy and computerized image analysis.

Collagen stands for the most abundant element of the extracellular matrix (ECM) and is responsible for maintaining skin tensile strength ${ }^{11,12}$. Due to its triple helix structure, which is not centrosymmetric, collagen is a very good SHG generator ${ }^{12-14}$ and the resultant images can be evaluated by computational analysis.

This study evaluated anisotropy, entropy and optical density. Anisotropy usually quantifies the degree of collagen fibers alignment within the dermis ${ }^{15}$ and can be used to study how it modifies, as skin ages or develops scars ${ }^{16}$. Entropy assesses the amount of disorderliness of a system and can be used to verify the randomness of an image. This was described previously for skin surface analysis ${ }^{17,18}$, as well as for the study of nerve aging ${ }^{19}$. Optical density is a well-known way to quantify the number of collagen fibers within an image ${ }^{20}$.

The aim of this experimental animal study is to use these collagen features obtained from SHG images in order to evaluate the dermal effects of using lower $\mathrm{CO}_{2}$ laser power associated with pulse stacking.

\section{Methods}

The study was approved by the board of the Ethical Committee of Animal Research (protocol \#3012-1).

Twenty male Wistar rats aging eight weeks were used. They were kept on a 12-hour light/dark cycle with free access to water and standard laboratory chow $\left(3,100 \mathrm{kcal} \cdot \mathrm{kg}^{-1}\right)$. All animals were anesthetized with $80 \mathrm{mg} \cdot \mathrm{kg}^{-1}$ ketamine plus $10 \mathrm{mg} \cdot \mathrm{kg}^{-1}$ xylazine injected intraperitoneally and positioned on dorsal decubitus. Their abdomens were shaved and stamped with four $15 \times 15 \mathrm{~mm}$ squares, $10 \mathrm{~mm}$ apart from each other to assure that one treatment area does not influence others. Then, the vertices of each square were tattooed for later area identification. Each square was assigned a number from one to four, as seen in the diagram (Fig. 1). Areas two, three and four were defined as treatment areas and area one was the control.

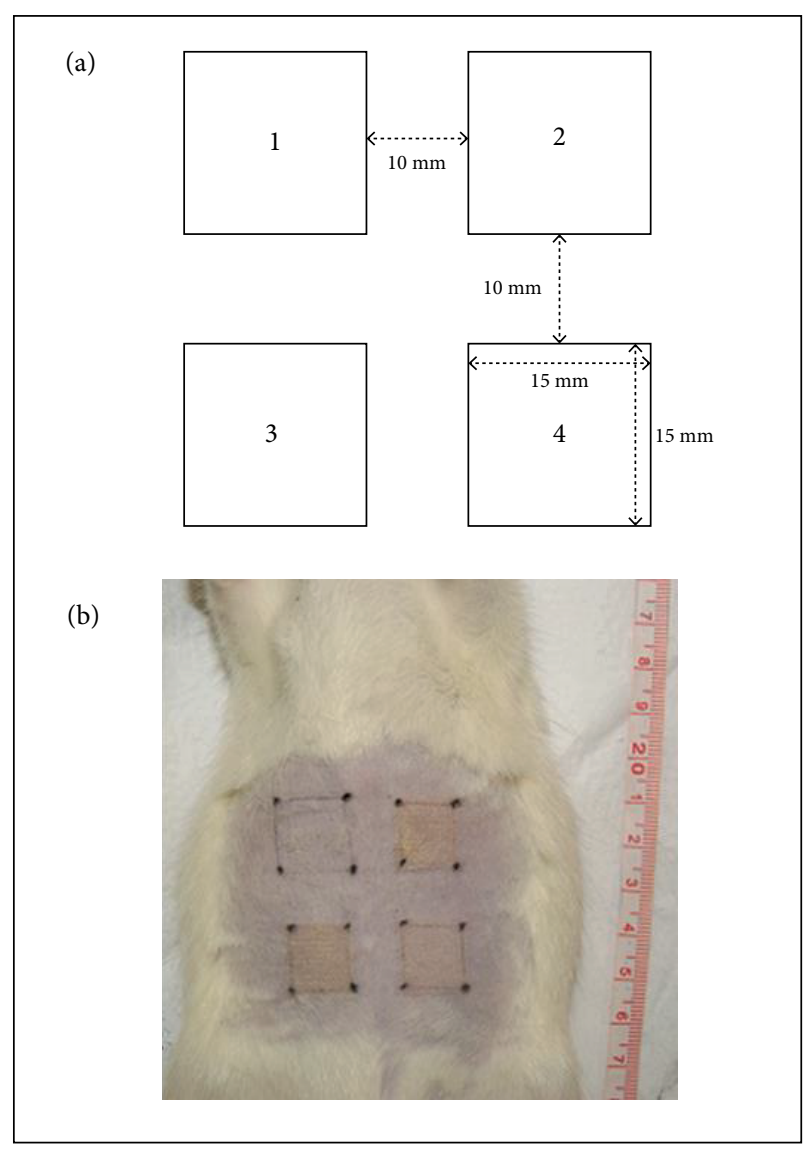

Figure 1 - Treatment areas. (a) Dimensions and arrangement; (b) Areas immediately after laser application. 


\section{Groups for analysis}

The 20 animals were divided into two groups.

Group 1 ( $n=10$ ) was sacrificed by anesthesia overdose 30 days after laser irradiation.

Group $2(n=10)$ was sacrificed 60 days post-procedure.

Each animal had all previously demarcated four areas collected for histological analysis.

Tissue specimens from both groups were fixed in $10 \%$ buffered formalin and embedded in paraffin. Then, a vertically cut $5 \mu \mathrm{m}$ slice was obtained from each area and stained using the hematoxylin and eosin method.

\section{Laser procedure}

Each treatment area received a single-pass $\mathrm{CO}_{2}$ fractional laser (Smartxide Dot; DEKA, Florence, Italy) with different parameters.

The $120 \mu \mathrm{m}$ spot size was used, as well as a $500 \mu \mathrm{m}$ spacing between MTZs for all areas in this study.

Other parameters, such as power, exposure time, stacking, fluence and energy per each MTZ, are summarized in Table 1.

Table 1 - Laser settings for each area.

\begin{tabular}{cccccc}
\hline Area & $\begin{array}{c}\text { Power } \\
(\boldsymbol{W})\end{array}$ & $\begin{array}{c}\text { Exposure } \\
\text { time ( } \boldsymbol{\mu s})\end{array}$ & Stack & $\begin{array}{c}\text { Fluence } \\
\left(\mathbf{J} \cdot \mathbf{c m}^{-2}\right)\end{array}$ & $\begin{array}{c}\text { Energy/ } \\
\mathbf{M T Z}(\mathbf{m})\end{array}$ \\
\hline 1 & - & - & - & - & - \\
\hline 2 & 30 & 900 & 1 & 3.74 & 27.0 \\
\hline 3 & 20 & 300 & 3 & 2.49 & 18.0 \\
\hline 4 & 10 & 300 & 3 & 1.87 & 13.5 \\
\hline
\end{tabular}

\section{Second harmonic generation image acquisition}

Second harmonic generation images were utilized to evaluate the collagen organization within all four areas. Images were acquired with an inverted Z.1 Axio Observer microscope equipped with a Zeiss LSM780 NLO confocal scanning head (Carl Zeiss AG, Jena, Germany) at the National Institute of Photonics Applied to Cell Biology. All samples were evaluated according to a protocol previously described by Utino ${ }^{21}$. To obtain a complete image of the slide, we acquired tile scans $(512 \times 512)$ that were stitched in larger mosaics, as seen in Fig. 2 .

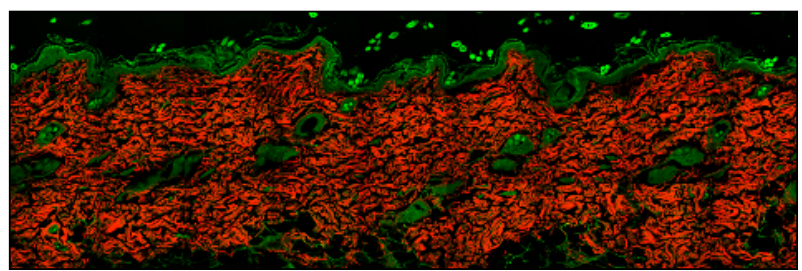

Figure 2 - Second harmonic generation scans stitched in mosaic.

\section{Image evaluation}

All images were analyzed using the free software ImageJ (National Institutes of Health, USA. http://www.imagej.nih.gov/ij) for collagen morphometric features. Collagen anisotropy, entropy and optical density were quantified. For each of these collagen features, a specific software plug-in is needed. All of them are already previously described for collagen analysis.

In order to measure anisotropy, we used the FibrilTool plug-in applied without any image pre-processing, as indicated by Boudaoud ${ }^{22}$.

Either for quantifying optical density and entropy, all images were split into color channels to obtain only the red channel, which is specific for the SHG signal.

To quantify collagen optical density, we clicked the "measurement" button under the "analyze" menu and the results were presented in the "results" window.

For entropy analysis, we used the grey level co-occurrence matrix (GLCM) texture analysis plug-in.

Each whole image was measured three times for each feature and averaged.

All data were tabulated on a sheet for further statistical analysis.

\section{Statistics}

The SAS system was used for statistical analysis. Areas within a group were compared using the Friedman test, while intergroup comparison was conducted by the Mann-Whitney test. The variables studied were anisotropy, density and entropy. The level of significance used in this study was $5 \%$.

\section{Results}

All images were assessed for three collagen features: anisotropy, entropy and density.

\section{Anisotropy}

In group 1 (30 days), all treatment areas showed decreased anisotropy when compared to the control area, but without statistical significance $(p=0.7891)$.

In turn, in group 2 (60 days), we observed an increased anisotropy for treatment areas three and four when compared to the control area. On the other hand, anisotropy values were lower in the treatment area two than in the control area. Again, no statistical significance was found $(p=0.7014)$. These results are shown in Fig. 3. 
(a)

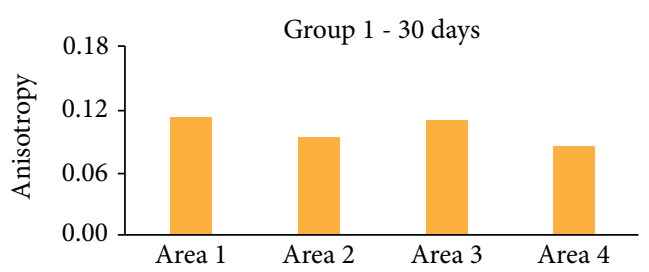

(b)

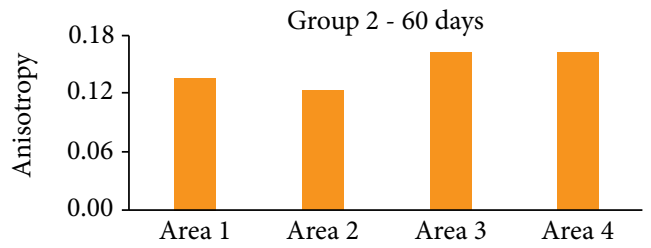

(c)

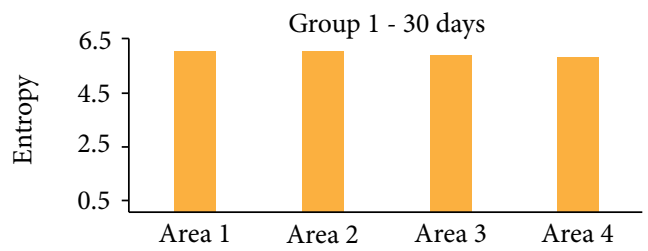

(d)

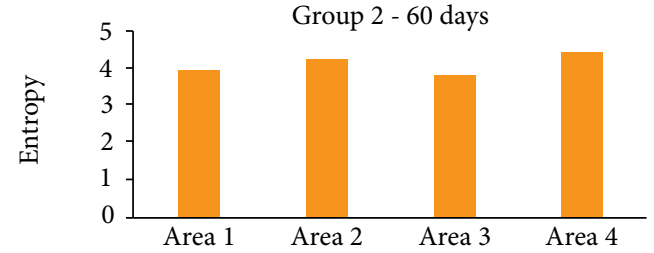

(e)

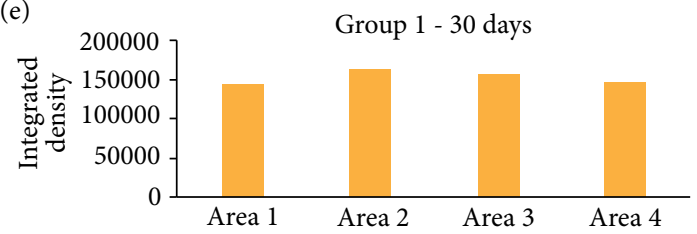

(f)

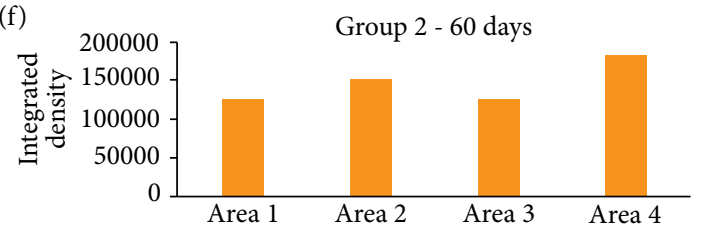

Figure 3 - (a) Anisotropy results for group 1; (b) Anisotropy results for group 2; (c) Entropy results for group 1; (d) Entropy results for group 2; (e) Integrated density results for group 1; (f) Integrated density results for group 1.

When comparing areas between the two groups, we show an increase in anisotropy overtime for all of them, including the control area. This increase was more evident in areas three and four, but only reached statistical significance in area four ( $p=0.0305)$.
The results for anisotropy comparison between the two groups studied are represented in Fig. 4.
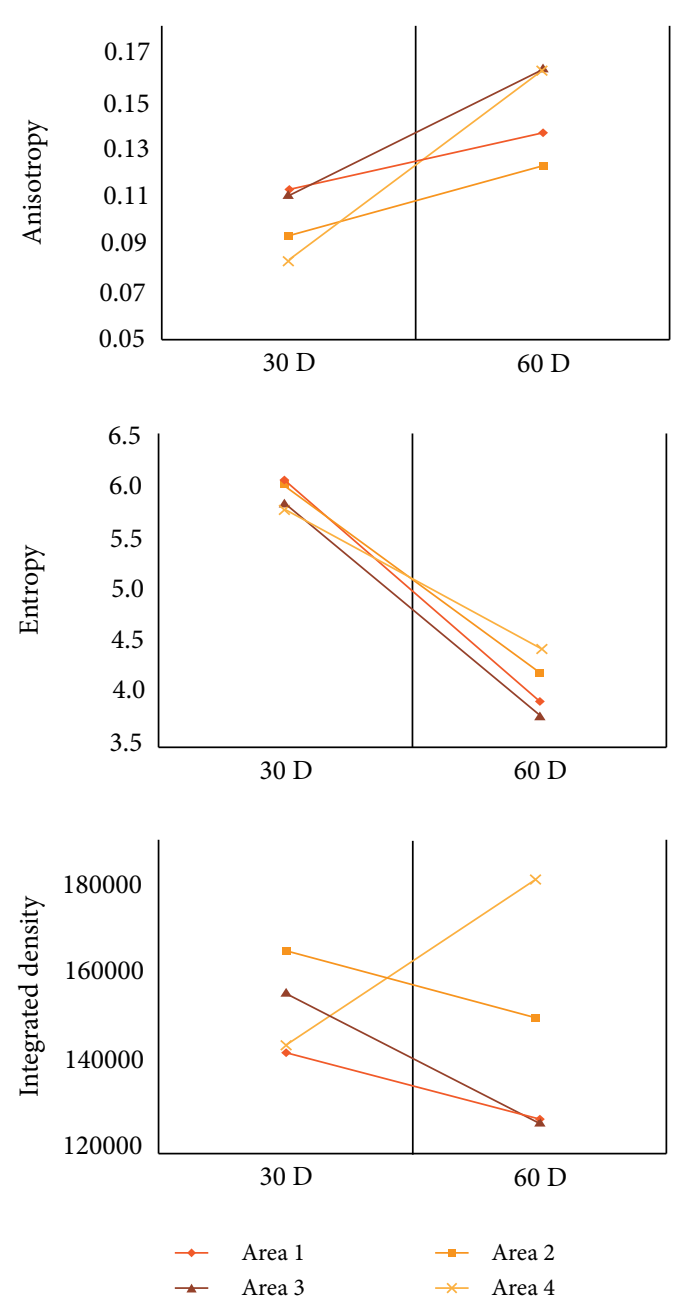

Figure 4 - Collagen features behavior over time.

\section{Entropy}

In group 1, there were no statistical differences between treatment areas and the control area ( $p=0.8497)$. The same pattern was observed in group $2(p=0.4551)$. These results are demonstrated in Fig. 3.

However, when comparing the groups, we noticed an overtime decrease in entropy for all areas. This decrease showed statistical significance for the control area $(p=0.004)$, area two $(p=0.0113)$ and area three $(p=$ $0.0013)$. Area four also showed a decrease in entropy, but without statistical significance $(p=0.1779)$. These results are demonstrated in Fig. 4. 


\section{Density}

In group 1, treatment areas two and three showed a slight increase in density compared to the control area. On the other hand, the treatment area four values were lower than the control area. However, no statistical significance was reached when comparing all areas $(p=0.4551)$ (Fig. 3$)$.

Group 2 demonstrated that all treatment areas increased density against the control, especially treatment area four. Despite this major increase in density in the treatment area four, no statistical significance was reached when comparing areas ( $p=0.2059$ ) (Fig. 3).

In intergroup comparison, we observed a decrease in density in the control area $(p=0.9674)$ and treatment areas two $(p=0.6232)$ and three $(p=0.7337)$. Treatment area four, in its turn, showed an overtime increased density $(p=0.6534)$. No statistical significance was reached (Fig. 4).

\section{Discussion}

Our study investigated the possibility of using lower power whereas associating pulse stacking to achieve collagen remodeling. For this purpose, we analyzed SHG images with Image free software, quantifying three collagen features: anisotropy, entropy and density. Together, they enable a structural evaluation of collagen changes after fractional $\mathrm{CO}_{2}$ laser treatment.

Since the early 90 s, the $\mathrm{CO}_{2}$ laser has evolved to become the gold standard for facial resurfacing ${ }^{1,2}$. It is possible to achieve impressive results in a single session due to its capability of skin contraction e collagen remodeling ${ }^{23}$. However, the long downtime for recovery, the risks for pigmentary disorders and unaesthetic scars rendered $\mathrm{CO}_{2}$ laser resurfacing a less useful tool for facial rejuvenation ${ }^{3}$.

The concept of fractional lasers emerged in $2004^{4}$ and its applicability to the $\mathrm{CO}_{2}$ laser was described by Hantash $^{5,6}$. Since then, many authors have studied its ability to successfully treat photoaging $7,8,24,25$, as well as other disorders like hypertrophic scars ${ }^{26,27}$ and acne scars ${ }^{28}$. The idea of deep ablating dermal tissue whereas leaving intact surrounding skin made it possible to deliver an excellent result while reducing significantly the risks and downtime ${ }^{5,29}$. However, achieving deep ablation usually requires higher power levels ${ }^{30}$. Despite its superior side effect profile over full ablative $\mathrm{CO}_{2}$ lasers, the fractional mode still presents some drawbacks, especially when higher power levels are used ${ }^{9}$. Avram ${ }^{31}$ advised for the risks of hypertrophic scaring when fractional $\mathrm{CO}_{2}$ laser resurfacing is used on the neck.

In the search for reducing, even more, the overall risk profile of fractional $\mathrm{CO}_{2}$ laser, an option could be reducing power levels while increasing the number of pulses delivered to each MTZ (stacking). Pulse stacking has been studied since long before the advent of the fractional laser. Fitzpatrick ${ }^{32}$, using a full ablative $\mathrm{CO}_{2}$ laser, found a greater potential for scaring due to the increased thermal injury observed with pulse stacking. On the other hand, when using a fractional $\mathrm{CO}_{2}$ laser, the use of consecutive pulses seems to be beneficial. Oni ${ }^{33}$ demonstrated that, by doubling a pulse using half the energy, the tissue does not dissipate heat between pulses. It results in deeper and narrower columns of ablation with relatively wider zones of coagulation. This pattern could yield good results with less downtime than single pulses.

To investigate this concept, a previous study from our group ${ }^{10}$ concluded that it is possible to achieve similar MTZ dimensions with lower power and pulse stacking. The same study showed increased tissue contraction overtime when these less aggressive parameters had been used. Prignano ${ }^{34}$, studying cytokine responses in tissue remodeling, also demonstrates that it is possible to achieve good biological results using lower power levels.

In order to corroborate our previous results, in this present experimental study we aimed to histologically characterize changes in collagen structure that could confirm the effects of using lower power and pulse stacking in collagen remodeling.

There are many methods to evaluate collagen within the dermis, including electron microscopy, biochemical and immunohistochemical analysis, among others ${ }^{35}$. A study conducted by Reilly ${ }^{36}$ demonstrated that the molecular effects of both fractional and fully ablative $\mathrm{CO}_{2}$ laser are very similar. This could explain the consistent rejuvenation obtained with the fractional mode. Other authors examined collagen behavior after $\mathrm{CO}_{2}$ exposure employing specific stains $^{37}$ or even by describing collagen changes in simple hematoxylin-eosin stains ${ }^{38}$. These methods, although largely used, many times are subject to subjective analysis ${ }^{14}$.

To overcome subjectivity, during the last decade several optical methods also had been developed, as confocal laser scanning, optical coherence tomography, and multiphoton microscopy, especially SHG microscopy ${ }^{39}$. All these methods provide images that can be further analyzed by image software, resulting in a more objective way to assess collagen behavior ${ }^{40}$.

In this study, SHG microscopy was employed to analyze collagen response to a fractional $\mathrm{CO}_{2}$ laser single treatment. Due to the collagen non-centrosymmetric molecular structure, it is an effective SHG generator ${ }^{41}$. The images obtained from SHG can be used to provide information on collagen structure within the $\mathrm{skin}^{42}$. Guo ${ }^{43}$ used SHG 
to investigate skin rejuvenation after treatment with a $1550 \mu \mathrm{m}$ fractional laser. They concluded that it is an appropriate technique to evaluate collagen regeneration by the fractional laser treatment. The same study observed that lower power treatment associated with a higher density of MTZ induces faster collagen regeneration.

The anisotropy index quantifies the degree of preferred alignment of collagen fibrils within the dermis ${ }^{44}$. This is important for understanding skin behavior. In this study, anisotropy was quantified using a plug-in from ImageJ software named FibrilTool. It was designed based on the concept of nematic tensor from the physics of liquid crystals to measure how well collagen fibrils are aligned. This enables image analysis without the complex processing needed with other techniques. Values obtained vary from 0 (random orientation - isotropic) to 1 (total alignment - anisotropic) $)^{22}$.

As skin ages, collagen fibers become more paralle ${ }^{16,45}$, and the same happens to the scar tissue ${ }^{14}$. This results in higher anisotropy values. Interestingly, the same pattern is present in newly formed collagen after photothermal treatments as observed by $\mathrm{Wu}^{44}$. Thus, we expected an increase in anisotropy for the laser-treated areas as indicative of neocollagenesis. We did not observe this pattern 30 days after treatment. In fact, a decreased anisotropy compared to the control area was noted. Dainichi ${ }^{46}$ also observed that an increased collagen alignment was present only after 35 to 58 days from laser treatment due to the initial collagen degeneration. This parallel arrangement of collagen fibers was also observed in vivo 90 days after fractional $\mathrm{CO}_{2}$ laser treatment using confocal microscopy ${ }^{47}$.

However, after 60 days, the two areas treated with lower power and pulse stacking increased anisotropy compared to the control area. This pattern was not observed in the area treated with the highest power in a single pulse. Although these results did not reach statistical significance, they could indicate that milder parameters can stimulate collagen synthesis, as observed by Prignano ${ }^{34}$.

We also compared anisotropy of all areas between 30 and 60 days. All areas including the control area increased anisotropy overtime. Concerning the control area, the increase, although not significant, is expected due to collagen alignment seen with aging ${ }^{16}$. The laser-treated areas experienced a greater increase in anisotropy from 30 to 60 days, but it only reached statistical significance $(p=0.0305)$ in the area treated with the mildest parameters. We hypothesize that these findings were detected only 60 days after laser treatment due to the prolonged effect on collagen structure seen after fractional laser treatments.
These long-term effects have been demonstrated immunohistochemically to last for up to six months ${ }^{6,48}$. Our results show a greater increase in anisotropy using less power and pulse stacking are in line with other authors. Yuan et al..$^{28}$ demonstrated that lower fluences can provide a significant efficacy for acne scars whereas Prignano ${ }^{38}$ found no advantage, both clinically and histologically, to use treatment with $4.15 \mathrm{~J} \cdot \mathrm{cm}^{-2}$ laser irradiation compared to those obtained with 2.07 and $2.77 \mathrm{~J} \cdot \mathrm{cm}^{-2}$.

Entropy is one of the features of the textural analysis, known as the GLCM, an effective method for quantitative analysis of skin texture ${ }^{49}$. It can be used to assess the level of randomness of a digital image ${ }^{18}$ and has been associated with the degree of fiber organization ${ }^{21}$. We used entropy to quantify collagen structure behavior in the SHG images obtained after $\mathrm{CO}_{2}$ fractional laser irradiation. With aging, the skin (and consequently collagen fiber arrangement) loses randomness, and entropy values decrease ${ }^{19}$. In this way, $\mathrm{CO}_{2}$ fractional laser treatment ideally should slow down this collagen arrangement loss of complexity. Analyzing entropy 30 days after laser irradiation, we noticed almost no differences among all areas. In turn, after 60 days, it was possible to observe an increased entropy, although not statistically significant, for the treatment areas two and four. These are, respectively, the areas where the highest and the lowest laser parameters were employed. Important data was found when we analyzed entropy from a temporal perspective. From 30 to 60 days after laser treatment, all areas including the control area showed decreased entropies. These results confirm the observations of Silva ${ }^{19}$, who demonstrated a loss of randomness with aging. The only area in which the entropy decrease was not statistically significant $(p=0.1779)$ was the area where de mildest parameters were employed. This result could indicate that by using lower power and associating stacked pulses, it is possible to slow down entropy decline overtime. To our knowledge, no previous study has evaluated collagen entropy on SHG images after fractional $\mathrm{CO}_{2}$ laser irradiation.

Integrated density is one of the most used parameters in SHG image analysis and an excellent form of collagen quantification. Its measures (the product of area and mean gray level) can be associated with the number of collagen fibers ${ }^{20}$. Collagen density decreases with aging, as it has been demonstrated both using regular stains ${ }^{50}$ and SHG microscopy ${ }^{51}$. In our study, almost all treated areas showed an increased collagen density when compared to the control area, but without statistical significance. But when density was analyzed over time, we observed that only the area where the mildest parameters were employed (area four) had an increase, 
whereas all the other areas showed the expected decreased density with aging ${ }^{39,51}$. These results also did not reach statistical significance, probably due to the small sample studied. Nevertheless, it still might indicate that it is possible to induce neocollagenesis using less aggressive laser settings.

It has been already demonstrated that fractional $\mathrm{CO}_{2}$ laser is clinically effective ${ }^{52}$. Tierney ${ }^{53}$ showed a $65.3 \%$ mean clinical improvement in lower lid laxity six months after two to three treatments. Another study with the same equipment used in this paper found a $52.4 \%$ mean improvement for overall cosmetic outcome after two to three sessions treating moderate to severe photoaging ${ }^{54}$. However, most of these studies show some degree of subjectivity when evaluating the results obtained.

Attempts to relate the clinical effects obtained with the application of fractional $\mathrm{CO}_{2}$ laser to changes in the dermis were also carried out with different methods. For example, $\mathrm{Ozog}^{37}$ used the Herovici stain to differentiate types I and III collagen using computation analysis of digital images evaluated after treating mature burn scars. Prignano ${ }^{38}$ provided a clinical to histological correlation using hematoxylin-eosin stains after a single treatment with a fractional $\mathrm{CO}_{2}$ laser device. Even the molecular mechanisms underlying fractional $\mathrm{CO}_{2}$ laser clinical outcomes were already studied ${ }^{36}$. The use of SHG signal to evaluate collagen responses to laser treatments was already studied by some authors ${ }^{43,44}$.

Our study, in its turn, uses SHG images to objectively evaluate collagen changes after fractional $\mathrm{CO}_{2}$ laser irradiation with lower power and pulse stacking. Although not conclusive, our results show a tendency that is in line with other authors ${ }^{33,38}$. Besides that, our findings corroborated our previous study ${ }^{10}$ on the macroscopic skin tightening observed using the same concept.

Further studies should investigate this theory within the human dermis to determine ideal laser settings balancing good results and low risks. In this way, SHG microscopy provides quantifiable measures for evaluation and can also be applied in vivo without the need for skin biopsies.

\section{Conclusion}

The combined results regarding anisotropy, entropy and density tend to demonstrate that it is possible to achieve collagen remodeling with the use of lower power levels associated with stacked pulses.

\section{Authors' contribution}

Intellectual and scientific content of the study: Motta MM, Stelini RF, Calderoni DR and Kharmandayan $P$; Design the study: Motta MM, Stelini RF, Calderoni $D R$ and Kharmandayan $P$; Critical revision: Calderoni DR and Kharmandayan $\mathrm{P}$; Acquisition and interpretation of data: Motta MM, Stelini RF, Calderoni DR and Damiani GV; Technical procedures: Motta MM and Gilioli R; Histopathological examinations: Stelini RF; Statistical analysis: Motta MM; Manuscript writing: Motta MM and Kharmandayan P.

\section{Data availability statement}

Data will be available upon request.

\section{Funding}

Not applicable.

\section{Acknowledgments}

Not applicable.

\section{References}

1. David LM, Lask GP, Glassberg E, Jacoby R, Abergel RP. Laser abrasion for cosmetic and medical treatment of facial actinic damage. Cutis. 1989;43(6):583-7.

2. Seckel BR, Younai S, Wang K-K. Skin tightening effects of the ultrapulse $\mathrm{CO}_{2}$ laser. Plast Reconstr Surg. 1998;102(3):8720-7. https://doi.org/10.1097/00006534199809030-00040

3. Nanni CA, Alster TS. Complications of carbon dioxide laser resurfacing. An Evaluation of 500 Patients. Dermatol Surg. 1998;24(3):315-20. https://doi. org/10.1111/j.1524-4725.1998.tb04161.x

4. Manstein D, Herron GS, Sink RK, Tanner H, Anderson RR. Fractional photothermolysis: A new concept for cutaneous remodeling using microscopic patterns of thermal injury. Lasers Surg Med. 2004;34(5):426-38. https://doi.org/10.1002/Ism.20048

5. Hantash BM, Bedi VP, Chan KF, Zachary CB. Ex vivo histological characterization of a novel ablative fractional resurfacing device. Lasers Surg Med. 2006;39(2):87-95. https://doi.org/10.1002/lsm.20405

6. Hantash BM, Bedi VP, Kapadia B, Rahman Z, Jiang K, Tanner H, Chan KF, Zachary CB. In vivo histological evaluation of a novel ablative fractional resurfacing device. Lasers Surg Med. 2007;39(2):96-107. https:// doi.org/10.1002/Ism.20468 
7. Tierney EP, Hanke WC, Petersen J. Ablative Fractionated CO2 Laser Treatment of Photoaging: A Clinical and Histologic Study. Dermatol Surg. 2012;38(11):1777-89. https://doi.org/10.1111/j.1524-4725.2012.02572.x

8. Gold MH, Biron JA. Combined superficial \& deep fractional skin treatment for photodamaged skin: a prospective clinical trial. J Cosmet Laser Ther. 2012;14(3):124-32. https://doi.org/10.3109/14764172.2012.670708

9. Shamsaldeen O, Peterson JD, Goldman MP. The adverse events of deep fractional $\mathrm{CO}_{2}$ : A retrospective study of 490 treatments in 374 patients. Lasers Surg Med. 2011;43(6):453-6. https://doi.org/10.1002/Ism.21079

10. Motta MM, Stelini RF, Calderoni DR, Gilioli R, Kharmandayan P. Lower energy and pulse stacking. A safer alternative for skin tightening using fractional $\mathrm{CO}_{2}$ laser. Acta Cir Bras. 2016;31(1):28-35. https:// doi.org/10.1590/S0102-865020160010000005

11. Naylor EC, Watson REB, Sherratt MJ. Molecular aspects of skin ageing. Maturitas. 2011;69(3):249-56. https://doi.org/10.1016/j.maturitas.2011.04.011

12. Puschmann S, Rahn C-D, Wenck H, Gallinat S, Fischer FF. Approach to quantify human dermal skin aging using multiphoton laser scanning microscopy. J Biomed Opt. 2012;17(3):036005. https://doi.org/10.1117/1. JBO.17.3.036005

13. Lutz V, Sattler M, Gallinat S, Wenck H, Poertner R, Fischer F. Characterization of fibrillar collagen types using multidimensional multiphoton laser scanning microscopy. Int J Cosmet Sci. 2012;34(2):209-15. https://doi. org/10.1111/j.1468-2494.2012.00705.x

14. Yildirim M, Quinn KP, Kobler JB, Zeitels SM, Georgakoudi I, Ben-Yakar A. Quantitative differentiation of normal and scarred tissues using second-harmonic generation microscopy. Scanning. 2016;38(6):684-93. https://doi. org/10.1002/sca.21316

15. Nickell S, Hermann M, Essenpreis M, Farrell TJ, Krämer $\mathrm{U}$, Patterson MS. Anisotropy of light propagation in human skin. Phys Med Biol. 2000;45(10):2873. https:// doi.org/10.1088/0031-9155/45/10/310

16. Wang H, Shyr T, Fevola MJ, Cula GO, Stamatas GN. Agerelated morphological changes of the dermal matrix in human skin documented in vivo by multiphoton microscopy. J Biomed Opt. 2018;23(3):030501. https:// doi.org/10.1117/1.JBO.23.3.030501

17. Jung G, Lee MY, Kim S, Lee J-B, Kim JG. Analysis of relation between skin elasticity and the entropy of skin image using near-infrared and visible light sources. J Biophotonics. 2020;13(1):e201900213. https://doi. org/10.1002/jbio.201900213

18. Breslavets A, Breslavets M, Shear NH. Quantification of randomness (Entropy) as a clinical tool to assess the severity of skin disease. Med Hypotheses. 2019;132:109311. https://doi.org/10.1016/j.mehy.2019.109311
19. Silva LEV, Senra Filho ACS, Fazan VPS, Felipe JC, Murta LO. Two-dimensional sample entropy analysis of rat sural nerve aging. 36th Annual International Conference of the IEEE Engineering in Medicine and Biology Society. Chicago: IEEE. 2014. https://doi.org/10.1109/EMBC.2014.6944339

20. Mostaço-Guidolin L, Rosin NL, Hackett T-L. Imaging collagen in scar tissue: Developments in second harmonic generation microscopy for biomedical applications. Int J Mol Sci. 2017;18(8):1772. https://doi.org/10.3390/ijms18081772

21. Utino FL, Garcia M, Velho PENF, França AFED, Stelini RF, Pelegati VB, et al. Second-harmonic generation imaging analysis can help distinguish sarcoidosis from tuberculoid leprosy. J Biomed Opt. 2018;23(12):126001. https://doi. org/10.1117/1.JBO.23.12.126001

22. Boudaoud A, Burian A, Borowska-Wykręt $D$, Uyttewaal $M$, Wrzalik R, Kwiatkowska D, et al. FibrilTool, an ImageJ plugin to quantify fibrillar structures in raw microscopy images. Nat Protoc. 2014;9(2):457-63. https://doi.org/10.1038/ nprot.2014.024

23. Baleg SMA, Bidin N, Suan LP, Ahmad MF, Lau P, Ahmad $M F S$, et al. The effect of $\mathrm{CO}_{2}$ laser treatment on skin tissue. J Cosmet Dermatol. 2015;14(3):246-53. https:// doi.org/10.1111/jocd.12142

24. Clementoni MT, Lavagno R, Munavalli G. A new multimodal fractional ablative $\mathrm{CO}_{2}$ laser for wrinkle reduction and skin resurfacing. J Cosmet Laser Ther. 2012;14(6):24452. https://doi.org/10.3109/14764172.2012.738918

25. Clementoni MT, Galimberti M, Tourlaki A, Catenacci $M$, Lavagno R, Bencini PL. Random fractional ultrapulsed $\mathrm{CO}_{2}$ resurfacing of photodamaged facial skin: long-term evaluation. Lasers Med Sci. 2013;28:643-50. https://doi. org/10.1007/s10103-012-1116-1

26. Lee S-J, Suh D-H, Lee J-M, Song K-Y, Ryu HJ. Dermal remodeling of burn scar by fractional $\mathrm{CO}_{2}$ laser. Aesthet Plast Surg. 2016;40:761-8. https://doi.org/10.1007/ s00266-016-0686-x

27. El-Zawahry BM, Sobhi RM, Bassiouny DA, Tabak SA. Ablative $\mathrm{CO}_{2}$ fractional resurfacing in treatment of thermal burn scars: an open-label controlled clinical and histopathological study. J Cosmet Dermatol. 2015;14(4):324-31. https://doi. org/10.1111/jocd.12163

28. Yuan X-H, Zhong S-X, Li S-S. Comparison study of fractional carbon dioxide laser resurfacing using different fluences and densities for acne scars in Asians: A randomized splitface trial. Dermatol Surg. 2014;40(5):545-52. https://doi. org/10.1111/dsu.12467

29. Rahman Z, MacFalls H, Jiang K, Chan KF, Kelly K, Tournas $\mathrm{J}$, et al. Fractional deep dermal ablation induces tissue tightening. Lasers Surg Med. 2009;41(2):78-86. https://doi.org/10.1002/Ism.20715

30. Omi T, Numano $\mathrm{K}$. The Role of the $\mathrm{CO}_{2}$ Laser and Fractional $\mathrm{CO}_{2}$ Laser in Dermatology. Laser Ther. 2014;23(1):49-60. https://doi.org/10.5978/islsm.14-RE-01 
31. Avram MM, Tope WD, Yu T, Szachowicz E, Nelson JS. Hypertrophic scarring of the neck following ablative fractional carbon dioxide laser resurfacing. Lasers Surg Med. 2009;41(3):185-8. https://doi.org/10.1002/Ism.20755

32. Fitzpatrick RE, Smith SR, Sriprachya-anunt S. Depth of vaporization and the effect of pulse stacking with a high-energy, pulsed carbon dioxide laser. J Am Acad Dermatol. 1999;40(4):615-22. https://doi.org/10.1016/ S0190-9622(99)70447-0

33. Oni G, Robbins D, Bailey S, Brown SA, Kenkel JM. An in vivo histopathological comparison of single and double pulsed modes of a fractionated $\mathrm{CO}_{2}$ laser. Lasers Surg Med. 2012;44(1):4-10. https://doi.org/10.1002/Ism.21150

34. Prignano F, Campolmi P, Bonan P, Ricceri F, Cannarozzo G, Troiano $\mathrm{M}$, et al. Fractional $\mathrm{CO}_{2}$ laser: a novel therapeutic device upon photobiomodulation of tissue remodeling and cytokine pathway of tissue repair. Dermatol Ther. 2009;22(Suppl 1):S8-15. https://doi.org/10.1111/j.15298019.2009.01265.x

35. Yasui T, Tohno $Y$, Araki T. Characterization of collagen orientation in human dermis by two-dimensional second-harmonic-generation polarimetry. J Biomed Opt. 2004;9(2):259-64. https://doi.org/10.1117/1.1644116

36. Reilly MJ, Cohen M, Hokugo A, Keller GS. Molecular effects of fractional carbon dioxide laser resurfacing on photodamaged human skin. Arch Facial Plast Surg. 2010;12(5):321-5. https://doi.org/10.1001/archfacial.2010.38

37. Ozog DM, Liu A, Chaffins $M L$, Ormsby $A H$, Fincher $E F$, Chipps LK, et al. Evaluation of clinical results, histological architecture, and collagen expression following treatment of mature burn scars with a fractional carbon dioxide laser. JAMA Dermatol. 2013;149(1):50-7. https://doi. org/10.1001/2013.jamadermatol.668

38. Prignano F, Bonciani D, Campolmi P, Cannarozzo G, Bonan P, Lotti T. A study of fractional $\mathrm{CO}_{2}$ laser resurfacing: the best fluences through a clinical, histological, and ultrastructural evaluation. J Cosmet Dermatol. 2011;10(3):210-6. https:// doi.org/10.1111/j.1473-2165.2011.00571.x

39. Wu S, Li H, Yang H, Zhang X, Li Z, Xu S. Quantitative analysis on collagen morphology in aging skin based on multiphoton microscopy. J Biomed Opt. 2011;16(4):040502. https:// doi.org/10.1117/1.3565439

40. van Zuijlen PPM, de Vries HJC, Lamme EN, Coppens JE, van Marle J, Kreis RW, et al. Morphometry of dermal collagen orientation by Fourier analysis is superior to multi-observer assessment. J Pathol. 2002;198(3):28491. https://doi.org/10.1002/path.1219

41. Yew E, Rowlands C, So PTC. Application of multiphoton microscopy in dermatological studies: A mini-review. J Innov Opt Health Sci. 2014;7(5):1330010. https://doi. org/10.1142/S1793545813300103

42. HansonKM,BardeenCJ.Application of nonlinearopticalmicroscopyforimagingskin. Photochem Photobiol.2009;85(1):33-44. https://doi.org/10.1111/j.1751-1097.2008.00508.x
43. Guo H-W, Tseng T-Y, Dong C-Y, Tsai T-H. Evaluation of fractional photothermolysis effect in a mouse model using nonlinear optical microscopy. J Biomed Opt. 2014;19(7):075004. https:// doi.org/10.1117/1.JBO.19.7.075004

44. Wu S-L, Li H, Zhang X-M, Chen WR, Wang Y-X. Character of skin on photo-thermal response and its regeneration process using second-harmonic generation microscopy. Lasers Med Sci. 2014;29:141-6. https://doi.org/10.1007/s10103-013-1296-3

45. Nguyen TT, Eklouh-Molinier C, Sebiskveradze D, FeruJ, Terryn C, Manfait $\mathrm{M}$, et al. Changes of skin collagen orientation associated with chronological aging as probed by polarizedFTIR micro-imaging. Analyst. 2014;139(10):2482-8. https:// doi.org/10.1039/c3an00353a

46. Dainichi $T$, Ueda S, Fumimori T, Kiryu H, Hashimoto $T$. Skin Tightening Effect Using Fractional Laser Treatment II: A pilot animal study on skin remodeling. Dermatol Surg. 2010;36(1):71-5. https://doi.org/10.1111/j.15244725.2009.01382.x

47. Longo C, Galimberti M, De Pace B, Pellacani G, Bencini PL. Laser skin rejuvenation: epidermal changes and collagen remodeling evaluated by in vivo confocal microscopy. Lasers Med Sci. 2013;28:769-76. https://doi. org/10.1007/s10103-012-1145-9

48. Xu X-G, Luo Y-J, Wu Y, Chen JZ, Xu T-H, Gao X-H, et al. Immunohistological evaluation of skin responses after treatment using a fractional ultrapulse carbon dioxide laser on back skin. Dermatol Surg. 2011;37(8):1141-9. https://doi.org/10.1111/j.1524-4725.2011.02062.x

49. Pang H, Chen T, Wang X, Chang Z, Shao S, Zhao J. Quantitative evaluation methods of skin condition based on texture feature parameters. Saudi J Biol Sci. 2017;24(3):514-8. https://doi.org/10.1016/j.sjbs.2017.01.021

50. Marcos-Garcés V, Aguilar PM, Serrano CB, Bustos VG, Seguí JB, Izquierdo AF, Ruiz-Saurí A. Age-related dermal collagen changes during development, maturation and ageing - a morphometric and comparative study. J Anat. 2014;225(1):98-108. https://doi.org/10.1111/joa.12186

51. Zhuo S, Zhu X, Chen J, Xie S. Quantitative biomarkers of human skin photoaging based on intrinsic second harmonic generation signal. Scanning. 2013;35(4):273-6. https://doi.org/10.1002/sca.21062

52. Tierney EP, Eisen RF, Hanke CW. Fractionated $\mathrm{CO}_{2}$ laser skin rejuvenation. Dermatol Ther. 2011;24(1):41-53. https://doi.org/10.1111/j.1529-8019.2010.01377.x

53. Tierney EP, Hanke CW, Watkins L. Treatment of lower eyelid rhytids and laxity with ablative fractionated carbon-dioxide laser resurfacing: Case series and review of the literature. J Am Acad Dermatol. 2011;64(4):73040. https://doi.org/10.1016/j.jaad.2010.04.023

54. Tierney EP, Hanke CW. Fractionated Carbon Dioxide Laser Treatment of Photoaging: Prospective Study in 45 Patients and Review of the Literature. Dermatol Surg. 2011;37(9):1279-90. https://doi.org/10.1111/j.1524-4725.2011.02082.x 